\title{
Danh sách tác phẩm, tác giả đoạt Giải báo chí quốc gia 2010
} 23:07)

Lễ trao Giải báo chí quốc gia lần thứ V - 2010 đã được tổ chức trang trọng tối 21/6/2011, tại Thủ đô Hà Nội. Dưới đây là danh sách toàn bộ các tác phẩm, tác giả, nhóm tác giả đoạt Giải (theo 8 loại Giải).

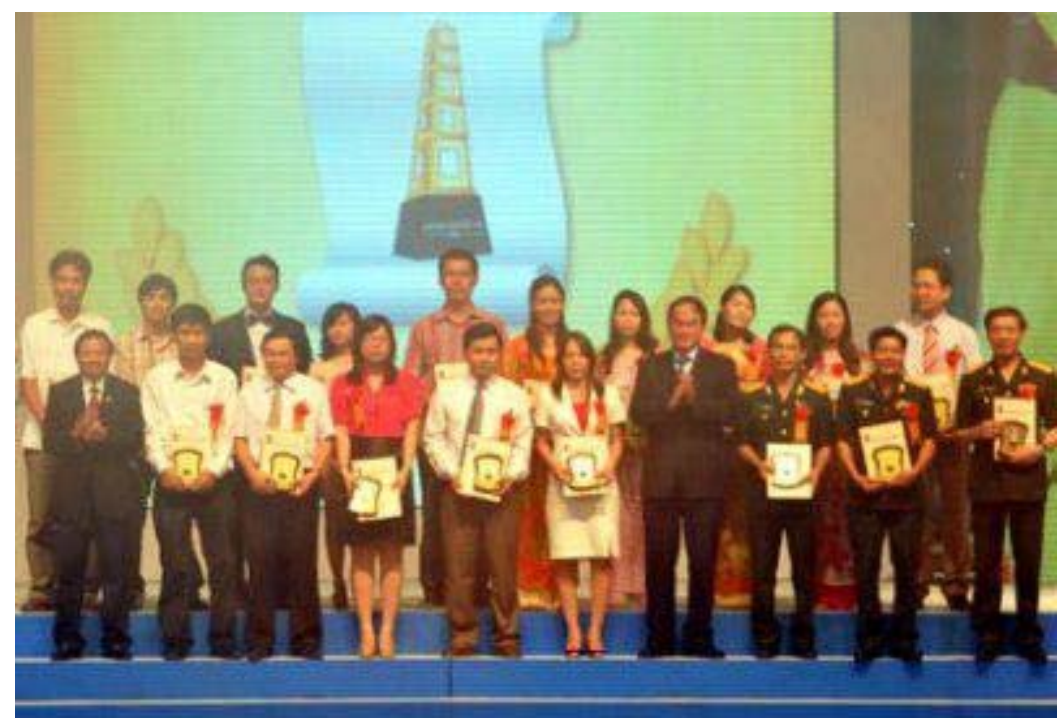

Phó Thủ tướng Nguyễn Thiện Nhân và Bộ trưởng Lê Doãn Hợp trao giải B

I - Giải Tin, bài phản ánh, phỏng vấn, ghi chép (báo in):

留 Giải A: 01 giải

- Tác giả: Nguyễn Đăng Lâm (Phân xã TTXVN tại Quảng Ngãi - Thông tấn xã Việt Nam) với loạt bài: Lý Sơn - Bảo tàng sống động về lịch sử chủ quyền của Việt Nam tại Hoàng Sa và Trường Sa.

战 Giải B: 05 giải

1. Nhóm tác giả: Trần Tuấn, Minh Thuỳ, Phạm Hùng ( $\mathrm{CH}$ Báo Tiền phong) với loạt bài: Những đại dự án FDI vốn ảo.

2. Nhóm tác giả: Dương Thanh Tùng, Quang Duẩn, Quý Tuấn, Hiển Cừ, Đức Huy, Trùng Dương, Nguyễn Phúc, Cao Bắc, Hải Âu (Báo Thanh Niên) với loạt bài: "Bức tử" lòng đất.

3. Nhóm tác giả: Phan Thị Hải Phương, Trần Ánh Tuyết (LCH Báo Nhân Dân) với loạt bài: Mồ hôi nước mắt trong hạt gạo đồng bằng sông Hồng.

4. Nhóm tác giả: Lê Phúc Nguyên, Nguyễn Huy Thiêm, Đặng Trung Hội (LCH Báo Quân đội nhân dân) với loạt bài: Giữ "phên giậu" Tây Nguyên. 
5. Nhóm tác giả: Nguyễn Triều, Trần Chiến, Nguyễn Ngọc Tiến, Lê Huy Anh, Lê Hoàng Anh, Đoàn Anh Tuấn, Cù Xuân Trường (Báo Hà Nội mới - HNB Thành phố Hà Nội) với loạt bài: Kinh đô và cố đô: Những dặm dài lịch sử.

6. Giải C: 06 giải

1. Nhóm tác giả: Phạm Tuyên, Thành Duy, Phạm Anh, Đại Dương ( $\mathrm{CH}$ Báo Tiền phong) với loạt bài: Cả nước khốn khổ vì ông độc quyền.

2. Tác giả: Đỗ Doãn Hoàng (CH Báo Lao động) với loạt bài: Về trùng tu và tôn tạo thành nhà Mạc.

3. Tác giả: Lâm Thị Ngọc Bích (Bích Ngọc) - (CH Báo Đất Việt) với loạt bài: Cứu dãy Trường Sơn.

4. Tác giả: Lý Ngọc Thanh (Ngọc Lý) - (Báo Tài nguyên và Môi trường) với loạt bài: Nghịch lý đất đô thị.

5. Nhóm tác giả: Lưu Vinh, Xuân Luận (Báo CAND - LCH Bộ Công an) với loạt bài: Bác Hồ với quyết định "Thà chặt một cành sâu để cho cây xanh tốt".

6. Tác giả: Đoàn Thị Mai Hương (Đoàn Mai Hương) - (Báo Sài Gòn giải phóng - Hội Nhà báo TP.HCM) với loạt bài: "Nhà giàn" trên biên cương.

Fiải Khuyến khích: 14 giải

1. Nhóm tác giả: Nguyễn Thị Thanh Hà (Thanh Hà) - (Báo Tuổi trẻ - Hội Nhà báo TP.HCM) với loạt bài: Ngô Bảo Châu - Duyên số với giải Fields.

2. Nhóm tác giả: Vũ Thục Trinh, Nguyễn Minh Ngọc (Minh Quân, Minh Ngọc) (Thời báo Ngân hàng LCH Ngân hàng) với loạt bài: Nỗi niềm tiền lẻ.

3. Tác giả: Nguyễn Văn Sinh (Hà Linh Quân - Báo Lao động) với loạt bài: Toàn cảnh Vinashin.

4. Tác giả: Bùi Vĩnh Cự (Vĩnh Cự) - (Báo Thừa Thiên Huế - HNB Thừa Thiên Huế) với loạt bài: Cận cảnh hiện trạng xâm hại di tích.

5. Nhóm tác giả: Việt Hằng, Việt Hương, Xuân Thiên (Báo Phụ nữ Thủ đô - HNB Thành phố Hà Nội) với loạt bài: Đau đầu vì rác.

6. Nhóm tác giả: Đinh Xuân Dũng, Hoàng Gia Minh (LCH Báo Quân đội nhân dân) với loạt bài: Quân đội tham gia chữa cháy rừng ở Lào Cai.

7. Tác giả: Phạm Vũ Quỳnh Hương (Phạm Vũ) - (Báo Tuổi trẻ - Hội Nhà báo TP.HCM) với loạt bài: Đảng trong dân.

8. Nhóm tác giả: Đỗ Việt Phương, Trần Việt Phương, Phạm Thái Cảnh (Báo Quảng Ninh - HNB Quảng Ninh) với loạt bài: Trạm cân xe Đại Yên. 
9. Tác giả: Phạm Thị Mỹ Hạnh (Hà An) - (Báo Đà Nã̃ng - HNB TP. Đà Nã̃ng) với loạt bài: Sổ đỏ, bao giờ lấy lại?

10. Tác giả: Nguyễn Thành (Báo Đà Nẵng - HNB TP. Đà Nã̃ng) với loạt bài: Đề án 89, chuyện 3 người.

11. Nhóm tác giả: Ngọc Quế, Hà Vi, Vị Thủy, Công Đạo, Vũ Úy (Báo Hải Dương - HNB Hải Dương) với loạt bài: Làm gì để người Việt thích dùng hàng Việt?

12. Nhóm tác giả: Hải Giang, Thu Hiền (Báo Hà Nội mới - HNB Thành phố Hà Nội) với loạt bài: Phố cổ Hà Nội: Ứng xử thế nào cho phải?

13. Tác giả: Nguyễn Trọng Tấn (Báo Âp Bắc - HNB Tiền Giang) với loạt bài: Nơi chiến tranh đi qua.

14. Tác giả: Nguyễn Thị Thanh Thuận (Thanh Thuận) - (Báo Quảng Ngãi - HNB Quảng Ngãi) với loạt bài: Nêu gương điển hình học tập và làm theo tấm gương đạo đức Hồ Chí Minh.

\section{II- Giải Xã luận, bình luận, chuyên luận (báo in):}

Giải A: Không có

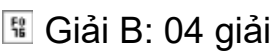

1. Nhóm tác giả: Đặng Lê Nguyên Vũ, Đinh La Thăng, Vương Quân Hoàng (Cộng tác viên Tạp chí Cộng sản) với loạt bài về tập đoàn kinh tế.

2. Tác giả: Cao Đức Thái (Lệ Chi) (Báo Quân đội nhân dân) với loạt bài: Đa đảng hay một đảng lãnh đạo cầm quyền - Đâu là chân lý?

3. Tác giả: Nguyễn Viết Thông (Hội đồng lý luận Trung ương - Cộng tác viên Báo Nhân Dân) với loạt bài: Công cuộc đổi mới ở Việt Nam do Đảng Cộng sản Việt Nam khởi xướng và lãnh đạo - những thành tựu to lớn, có ý nghĩa lịch sử.

4. Nhóm tác giả: Trần Thế Tuyển, Nguyễn Thế Nghĩa, Vũ Khoan, Ái Chân, Mai Hương (Hội Nhà báo TP.HCM) với loạt bài: Đổi mới để phát triển - Đường chúng ta đi.

竪 Giải C: 05 giải

1. Nhóm tác giả: Võ Tòng Xuân, Ngô Đức Thanh, Nguyễn Doãn Thị Liễu (Cộng tác viên Tạp chí Cộng sản) với loạt bài về thị trường cho nông sản Việt Nam.

2. Tác giả: Hoàng Chí Bảo (Hội đồng Lý luận Trung ương - Cộng tác viên Tạp chí Lịch sử Đảng) với loạt bài: Mối quan hệ giữa đổi mới kinh tế và đổi mới chính trị - nhìn từ thực tiễn Việt Nam.

3. Tác giả: Bùi Đức Lại (Ban Tổ chức Trung ương - Cộng tác viên Tạp chí Xây dựng Đảng) với loạt bài: Chạy chức và trách nhiệm. 
4. Nhóm tác giả: Nguyễn Ngọc (Nguyễn Ngọc Hồi), Đức Lê (Lê Đức Cường), Thanh Tâm (Nguyễn Học Từ) ( $\mathrm{CH}$ Tạp chí Quốc phòng toàn dân) với loạt bài: Chống "Diễn biến hoà bình" - Nhìn từ góc độ dân chủ, nhân quyền.

5. Tác giả: Lê Vũ Hội (LCH Thông tấn xã Việt Nam) với loạt bài: Nguy cơ chiến tranh tiền tệ toàn cầu.

熙 Giải Khuyến khích: 11 giải

1. Tác giả: Nguyễn Chí Dũng - $\mathrm{CH}$ Tạp chí Khoa học quân sự với loạt bài: Tăng cường hợp tác quốc phòng ASEAN vì một khu vực ổn định và phát triển.

2. Tác giả: Vũ Sơn Thủy (Sơn Thủy) - CH Báo Thế giới \& Việt Nam với loạt bài: Chiến tranh Internet.

3. Tác giả: Nguyễn Trọng Bình - CH Tạp chí Lý luận Chính trị và Truyền thông với loạt bài: Nâng cao hiệu quả phản biện xã hội của báo chí ở nước ta hiện nay.

4. Nhóm tác giả: Lương Thị Vân Anh (Vân Anh), Phan Thị Thanh Quý (Thanh Quý) - CH Báo Pháp luật Việt Nam với loạt bài: Nhà báo tác nghiệp, có phải là công vụ?

5. Nhóm tác giả: Tương Lai, Dương Xuân Ngọc, Trần Đình Huỳnh, Cao Đức Thái, Nguyễn Viết Chức CH Báo Đại đoàn kết với loạt bài: Ỷ Đảng - Lòng dân.

6. Tác giả: Đặng Tài Tính (Ban Tôn giáo Chính phủ - Cộng tác viên LCH Bộ Công an) với loạt bài: Nhân quyền, tự do tôn giáo ở Việt Nam - Sự thật không thể xuyên tạc.

7. Tác giả: Lê Minh Hùng (Nguyên Châu) - HNB TP. Đà Nã̃ng với loạt bài: Thư ngỏ gởi ngài Cao Quang Ánh.

8. Nhóm tác giả: Xuân Phú, Kim Loan, Kim Ngân - HNB Đồng Nai với loạt bài: Thương hiệu cho hàng Việt - Con đường chinh phục người tiêu dùng.

9. Tác giả: Lại Văn Long (Trọng Đức) - Hội Nhà báo TP.HCM với loạt bài: 35 năm văn thơ người Việt ở nước ngoài (1975 -2010) "Hồn Việt" hướng về Tổ quốc.

10. Tác giả: Lâm Chí Công - CH Báo Lao động với loạt bài: Về sự xuống cấp đạo đức trong một bộ phận người trẻ hôm nay.

11. Tác giả: Trần Thanh Hương (Thanh Hương) - (CH Báo Công thương) với loạt bài: Bình ổn giá: Những câu hỏi chưa có lời giải.

\section{III - Giải Phóng sự, phóng sự điều tra, bút ký báo chí (báo in):}

fị Giải A: 01 giải

- Nhóm tác giả: Ngô Mai Phong, Trần Ngọc Duy, Lê Quỳnh Trang, Tống Văn Thanh (CH Báo Lao động) 
với loạt bài: Về vụ tổ chức cướp than động trời tại Quảng Ninh.

䜿 Giải B: 02 giải

1. Nhóm tác giả: Trần Thanh Phong, Sông Lam, Thanh Bình, Nguyễn Hưng, Hồng Phú, Lê Quân, Hữu Toàn (Báo CAND - LCH Bộ Công an) với loạt bài: Từ vùng bão lũ miền Trung - Đi tìm giải pháp sống an toàn.

2. Nhóm tác giả: Nguyễn Hồng Cường (Hồng Cường), Lê Văn Bình (Lê Bình) (Báo Công an TP.Hồ Chí Minh - Hội Nhà báo TP.HCM) với loạt bài: Đột nhập "lãnh địa" cần sa.

fำ Giải C: 08 giải

1. Tác giả: Nguyễn Thu Hà (Báo Le Courrier du Vietnam - LCH Thông tấn xã Việt Nam) với loạt bài: Người Việt nhập cư bất hợp pháp vào Anh.

2. Tác giả: Nguyễn Tuấn Anh (Bắc Hà) - CH Báo Thanh tra, với loạt bài: Nha Trang, Khánh Hoà: Hành trình của dự án trái pháp luật.

3. Tác giả: Hoài Nam (CH Báo Thanh Niên) với loạt bài: Hãi hùng "công nghệ" trồng rau muống.

4. Nhóm tác giả: Nguyễn Quang Sang, Nguyễn Quang Phúc (Báo Công an TP.Đà Nẵng - HNB TP. Đà Nẵng) với loạt bài: Trả giá vì thủy điện.

5. Nhóm tác giả: Nguyễn Quang Vinh và Trần Ngọc Tú (Báo Tin tức - LCH Thông tấn xã Việt Nam) với loạt bài về Vinashin.

6. Tác giả: Lê Thiết Hùng (Nhất Ngôn) (LCH Báo Quân đội nhân dân) với loạt bài: Trường Sa - Tình biển duyên bờ.

7. Tác giả: Hoàng Thiên Nga (Ban đại diện Báo Tiền phong tại Tây Nguyên - HNB Đắk Lắk) với loạt bài: Dân nghèo sập bẫy cò ngân hàng.

8. Nhóm tác giả: Mai Xuân Nghiêm, Hoàng Anh (CH Báo Nông nghiệp Việt Nam) với loạt bài: Thanh niên nông thôn đang nghĩ gì?

匯 Giải Khuyến khích: 16 giải

1. Nhóm tác giả: Bá Kiên, Thanh Hằng (CH Báo Tiền phong) với loạt bài: "Nhật ký bằng tranh".

2. Tác giả: Xuân Xe (Báo CAND - LCH Bộ Công an) với loạt bài: Nhức nhối tội phạm người nước ngoài phạm tội.

3. Nhóm tác giả: Hoàng Tuấn, Trương Huyền, Nguyễn Long ( $\mathrm{CH}$ Báo Thanh Niên) với loạt bài: Thế thân ở sòng bạc Campuchia. 
4. Tác giả: Phạm Hoài Nam (Hoài Nam) (Báo Sài Gòn giải phóng - Hội Nhà báo TP.HCM) với loạt bài: Thực trạng các vườn quốc gia: rừng... chết.

5. Tác giả: Lưu Trọng Phú (Báo Bà Rịa - Vũng Tàu - HNB Bà Rịa-Vũng Tàu) với loạt bài: Phá núi lớn, làm đường trái phép.

6. Tác giả: Trần Thị Hằng (Mimoza Trần) - cơ quan đại diện Đài TNVN tại TP.HCM - Cộng tác viên Báo Xây dựng, với loạt bài: Trở lại Dự án đường vành đai Tân Sơn Nhất - Bình Lợi: Con đường không "ngay thẳng".

7. Tác giả: Trịnh Xuân Quang (Xuân Quang) - (CH Báo Lao động) với loạt bài: Vượt muôn ngàn sóng dữ.

8. Nhóm tác giả: Đình Thắng, Ngọc Minh, Mai Hương, Linh An (CH Báo Nông thôn ngày nay) với loạt bài: WFF đưa cá tra vào danh sách đỏ.

9. Tác giả: Lê Thuỳ Linh (Anh Đào) - Báo Điện tử VnMedia - LCH Thông tin và Truyền thông với loạt bài về Sốt đất $\mathrm{Ba} V \mathrm{~V}$.

10. Nhóm tác giả: Sáu Nghệ, Hồng Lĩnh, Phong Cầm, Tiến Hưng ( $\mathrm{CH}$ Báo Tiền phong) với loạt bài: Những người chống lại quan tham.

11. Tác giả: Đỗ Đình Dũng (BD: Tạ Nguyên) (Báo Đồng Nai - HNB Đồng Nai) với loạt bài: Giật mình với trạm thu phí giao thông.

12. Tác giả: Đặng Thị Hàn Ni (Hàn Ni) - (Báo Sài Gòn giải phóng - Hội Nhà báo TP.HCM) với loạt bài: Nghịch lý doanh nghiệp báo cáo lỗ.

13. Nhóm tác giả: Đào Ngọc Dũng (Ngọc Dũng), Lê Bảo Trung (Bảo Trung), Hoàng Mạnh Hùng (Hoàng Hùng) - (LCH Báo Nhân Dân) với loạt bài: "Tam Nông" trên vùng đồi, núi.

14. Tác giả: Đoàn Hữu Trung (Phân xã TTXVN tại Quảng Ngãi - HNB Quảng Ngãi) với loạt bài: Về 9 ngư dân "mất tích" trên biển Đông.

15. Tác giả: Hà Thị Thanh Thúy (BD: Thanh Thúy) - (Báo Đồng Nai - HNB Đồng Nai) với loạt bài: Hành trình của những số phận da cam.

16. Tác giả: Nguyễn Đào Phương (Báo Hà Nam - HNB Hà Nam) với loạt bài: Khi nhà nông... không ruộng.

IV - Giải Ảnh báo chí:

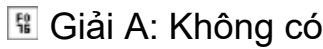

問 Giải B: 02 giải 
1. Tác giả: Nguyễn Thư Hà (Ngọc Nga) - Báo Tuổi trẻ - HNB TP. Hồ Chí Minh với tác phẩm ảnh: Chuyện bé Hạnh.

2. Tác giả: Phương Hoa - LCH Thông tấn xã Việt Nam với tác phẩm ảnh: "Sức sống Trường Sa".

战 Giải C: 03 giải

1. Tác giả: Quang Nhựt - LCH Thông tấn xã Việt Nam với tác phẩm ảnh đơn: Quyết liệt.

2. Tác giả: Nguyễn Minh Trường (Minh Trường) - LCH Báo Quân đội nhân dân với tác phẩm ảnh: Quảng trường Ba Đình ngày hội lớn.

3. Tác giả: Hồ Sĩ Minh (Sĩ Minh) - HNB Nghệ An với tác phẩm ảnh: Cận cảnh vùng rốn lũ.

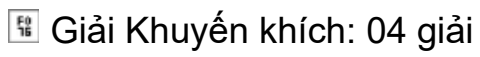

1. Tác giả: Hoàng Thống Nhất (Ban biên tập Ảnh TTXVN) với tác phẩm ảnh đơn: Hỏa hoạn tại công ty trách nhiệm hữu hạn Keo Đỉnh vàng.

2. Tác giả: Nguyễn Quốc Khánh (Ban biên tập Ảnh TTXVN) với tác phẩm ảnh đơn: Pha đánh được tính 3 điểm.

3. Tác giả: Nguyễn Ngọc Hà (Ban biên tập Ảnh TTXVN) với tác phẩm nhóm ảnh: Điện sáng Tây Bắc.

4. Tác giả: Nguyễn Thanh Dũng - HNB Cà Mau với tác phẩm ảnh: Thắp sáng nhà giàn Bãi Cạn Cà Mau.

V - Giải Phát thanh dành cho Tin, bài phản ánh, phỏng vấn, tọa đàm, bình luận, chuyên luận:

媐 Giải A: Không có

熙 Giải B: 01 giải

- Nhóm tác giả: Lê Văn Phúc, Nguyễn Hương Lan, Đỗ Thu Lan, Hà Bích Thuận (VOV1 - LCH Đài Tiếng nói Việt Nam) với loạt bài: Lạm phát thủy điện và những hệ lụy.

舆 Giải C: 03 giải

1. Tác giả: Phạm Minh Huệ - HNB Đắk Lắk với loạt bài: Tìm lời giải cho Tây Nguyên thêm xanh.

2. Tác giả: Tiến Đức (VOV1 - LCH Đài Tiếng nói Việt Nam) với loạt bài: Sốt vàng, đô la Mỹ (USD) và câu chuyện điều hành.

3. Nhóm tác giả: Thái Anh, Xuân Long, Kiều Hoanh, Tấn An - HNB Quảng Ngãi với loạt bài: Ngư dân Quảng Ngãi bám biển khơi xa. 


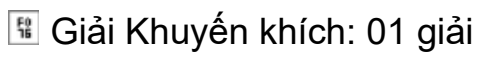

- Tác giả: Đức Thành (VOV1 - LCH Đài Tiếng nói Việt Nam) với loạt bài: Theo dòng thời sự: Từ VINASHIN nghĩ về câu chuyện quản lý và tái cấu trúc các tập đoàn kinh tế, doanh nghiệp Nhà nước.

VI - Giải Phát thanh dành cho Phóng sự, phóng sự điều tra, bút ký phát thanh:

Fiải A: Không có

器 Giải B: 01 giải

- Nhóm tác giả: Hồ Minh Khánh - Bùi Thị Hương Giang (VOV1 - LCH Đài Tiếng nói Việt Nam) với loạt bài: Mệnh lệnh vươn khơi.

闇 Giải C: 06 giải

1. Tác giả: Hà Nho - Thu Thùy (VOV1 - LCH Đài Tiếng nói Việt Nam) với loạt bài: Căn nguyên cơn sốt đất Hà Nội và vấn đề quản lý.

2. Tác giả: Nguyễn Thế Dũng (Thế Dũng) - HNB Ninh Bình, với tác phẩm: Mai sau - "Xẩm" liệu có còn?

3. Tác giả: Trần Đình Tường Lam - HNB Đồng Nai với tác phẩm: Chị em da cam.

4. Nhóm tác giả: Xuân Báu, Văn Thành - Hội Nhà báo Hà Tĩnh, với tác phẩm: Khi đồng ruộng bị vá chằng vá đụp.

5. Tác giả: Nguyễn Văn Thế (Văn Thế) - HNB Lâm Đồng với tác phẩm: Làng lâm tặc giữ rừng.

6. Tác giả: Lê Anh Vinh - HNB Quảng Ngãi với tác phẩm: Những hùng binh Hoàng Sa ngày nay.

Fiải Khuyến khích: 03 giải

1. Tác giả: Vũ Thị Mai - HNB Đồng Nai với tác phẩm: Hà Nội những ngày Tháng 8.

2. Tác giả: Lê Thị Bích Vân - HNB Vĩnh Long với loạt bài: Ông To cùng những "câu chuyện nhỏ".

3. Tác giả: Lâm Thanh Các (Thanh Các) - HNB Cần Thơ với tác phẩm: Liên kết hợp tác - Yếu tố để thành công.

VII - Giải báo hình dành cho Bình luận, tọa đàm, giao lưu, phim tài liệu:

Eiải A: Không có 
䶅 Giải B: 04 giải

1. Nhóm tác giả: Ngọc Dũng, Như Phong - HNB Nghệ An với tác phẩm: Chuyện bây giờ phải nói.

2. Nhóm tác giả: Bạch Dương, Hương Giang, Hữu Bằng, Thu Phương - LCH Đài Truyền hình Việt Nam với tác phẩm: Tham nhũng - Nếu bạn chấp nhận.

3. Nhóm tác giả: Lưu Quỳ, Hoàng Ngọc Mỹ, Phạm Minh Tuấn - CH Điện Ảnh Quân đội, với tác phẩm: Hoàng Sa trong lòng Tổ quốc.

4. Tác giả: Lê Minh - HNB Thành phố Hà Nội với tác phẩm: Một tình yêu Hà Nội.

鼠 Giải C: 05 giải

1. Nhóm tác giả: Nguyễn Kha Thoa, Đào Thị Hồng Lĩnh, Giang Văn Hải, Đỗ Chí Khoa - LCH Đài Truyền hình kỹ thuật số VTC với tác phẩm: Cách tiếp cận cộng đồng để bắt đầu một mô hình Nông thôn mới.

2. Nhóm tác giả: Nguyễn Văn Ngọc (Nguyễn Ngọc), Nguyễn Xuân Hoàng (Xuân Hoàng) - HNB Cần Thơ với tác phẩm: Hãy tin tôi một lần.

3. Nhóm tác giả: Nguyễn Thu Hằng, Vương Khánh Luông - LCH Bộ Văn hoá - Thể thao - Du lịch với tác phẩm: Chuyện của Nhã.

4. Nhóm tác giả: Nam Chung, Văn Thịnh, Thái Thanh, Hồng Xiêm, Anh Tú, Thái Học - Truyền hình CAND - LCH Bộ Công an với tác phẩm: Phải sống.

5. Nhóm tác giả: Nguyễn Minh Bảo (Minh Bảo), Lê Văn Tư (Lê Tư), Nguyễn Ngọc Hải (Ngọc Hải) - Hội Nhà báo TP.HCM với tác phẩm: Rừng gọi.

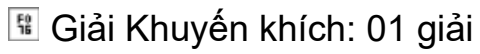

- Nhóm tác giả: Trần Thanh Thảo, Xuân Huy, Nguyễn Tuân, Đỗ Thịnh, Thu Hương, Ngọc Điệp - LCH Đài Truyền hình kỹ thuật số VTC với tác phẩm: Đồng tính.

VIII - Giải báo hình dành cho Tin, phóng sự, phóng sự điều tra:

竪 Giải A: Không có

媐 Giải B: 05 giải

1. Tác giả: Trần Cao Đạt - HNB Bến Tre với tác phẩm: Đời người - Đời dừa.

2. Tác giả: Bùi Quốc Hoằng (Quốc Hoằng) - HNB Ninh Bình với tác phẩm: Người công giáo Kim Sơn 
làm theo lời Bác.

3. Nhóm tác giả: Lê Mai, Lê Huy, Dương Diệu Hoàn - HNB Quảng Bình với tác phẩm: Tình người trong Iũ.

4. Tác giả: Phan Quang Lự - HNB Nam Định với tác phẩm: "Vua ngao".

5. Nhóm tác giả: Huỳnh Hùng, Hồng Quang Năm, Lâm Khánh, Lê Tuấn, Huy Quang - HNB TP. Đà Nẵng với tác phẩm: Từ chuyện ở Cồn Dầu.

熙 Giải C: 07 giải

1. Nhóm tác giả: Thùy Giang, Hồng Phương - HNB Lâm Đồng với tác phẩm: Cây "hai trong một".

2. Nhóm tác giả: Minh Quang, Liên Minh, Đức Sơn - LCH Đài THVN với tác phẩm: Trả nợ rừng.

3. Nhóm tác giả: Quý Hòa, Văn Thân - HNB Thừa Thiên Huế với tác phẩm: Tìm lại ước mơ.

4. Nhóm tác giả: Mai Bửu Hoàng Hưng (Hoàng Hưng), Chu Duy Hiếu (Duy Hiếu), Nguyễn Trường Sơn - Hội Nhà báo TP.HCM với tác phẩm: Tự hào chiến sĩ DK1.

5. Nhóm tác giả: Nguyễn Vĩnh Quyên, Nguyễn Hồng Quân, Vũ Thị Kim Thoa, Đinh Trung Dũng, Vũ Trọng Đại, Nguyễn Phương Thảo - (Hệ Phát thanh có hình - LCH Đài Tiếng nói Việt Nam) với tác phẩm: Bảo mẫu của làng phong.

6. Nhóm tác giả: Lê Trọng, Ngọc Dũng - HNB Lâm Đồng với tác phẩm: Mộc bản "Chiếu dời đô" - Một phát hiện bất ngờ.

7. Nhóm tác giả: Mạnh Hùng, Xuân Quỳnh - HNB Tuyên Quang với tác phẩm: Chuyện về những người hiến đất xây trường.

闓 Giải Khuyến khích: 09 giải

1. Tác giả: Nguyễn Giang Sơn - LCH Đài THVN với tác phẩm: Chuyện cô gái Mường.

2. Nhóm tác giả: Đỗ Thị Hiền, Mạnh Nghịch - HNB Thái Nguyên với tác phẩm: Sai phạm trong xây nhà 167 ở xã Yên Lạc, Phú Lương, Thái Nguyên.

3. Nhóm tác giả: Tuấn Minh, Thanh Thế - Đài PT\&TH Bạc Liêu - HNB Bạc Liêu với tác phẩm: Tiếng vọng từ những cánh rừng.

4. Tác giả: Nguyễn Thị Thu Trang - HNB Vĩnh Long với tác phẩm: Cổ tích mồ côi.

5. Nhóm tác giả: Nguyễn Tiến Vinh, Nguyễn Văn Bảo, Hoàng Thanh Hoa - LCH Biên phòng với tác phẩm: Không chỉ là lời hứa. 
6. Nhóm tác giả: Phạm Thị Thanh (Ninh Thanh), Nguyễn Việt Thắng (Việt Thắng) - HNB Thái Bình với tác phẩm: Người cho cá Vược "ngủ đông".

7. Nhóm tác giả: Xuân Thủy, Tiến Đạt - Hội Nhà báo Phú Thọ với tác phẩm: Xây nhà, trồng cây trái phép... để kiếm tiền giải phóng mặt bằng.

8. Nhóm tác giả: Hoàng Thuyên, Minh Huy - HNB Quảng Ngãi với tác phẩm: Lũ không đến từ sông.

9. Nhóm tác giả: Phương Thảo, Hiền An, Mạnh Hà - HNB Gia Lai với tác phẩm: "Bức tử" sông Ba.

Trao giấy chứng nhận cho các tác giả, nhóm tác giả của 33 tác phẩm vào vòng chung khảo Giải báo chí quốc gia năm 2010, nhưng không đoạt giải:

1. Tác giả: Thu Phương (Báo Tuổi trẻ Thủ đô - Hội Nhà báo TP. Hà Nội) với loạt bài: Nhiều sai phạm nghiêm trọng về quản lý đất đai ở huyện Thạch Thất - Hà Nội.

2. Nhóm tác giả: Nguyễn Thế Thịnh, Quang Nam, Bùi Xuân (Báo Thanh niên) với loạt bài: Bí thư Chi bộ luân chuyển.

3. Tác giả: Lê Thị Hồng Vân (Hồng Vân) (Báo Nhân Dân) với loạt bài: Giáo dục đại học - Bức tranh đáng báo động.

4. Tác giả: Hà Thu Thủy (HNB Bình Thuận) với tác phẩm: Một ngàn đồng... được một ngôi nhà.

5. Nhóm tác giả: Nguyễn Ngọc Sơn (Ngọc Sơn), Trần Thị Mỹ Duyên (Mỹ Thanh) (Hội Nhà báo TP. Hồ Chí Minh) với loạt bài: Đêm đấu giá từ thiện giúp đồng bào lũ lụt miền Trung: 74 tỷ đồng là không có thật.

6. Nhóm tác giả: Trần Ngọc Hưởng, Nguyễn Mạnh Hùng (HNB Hà Nam) với tác phẩm: Nông nghiệp Hà Nam ứng phó với biến đổi khí hậu.

7. Nhóm tác giả: Duy Phong, Gia Bảo, Võ Hoàng, Vũ Quang ( $\mathrm{CH}$ Báo Kinh tế Nông thôn) với loạt bài: Rừng phòng hộ - "cuộc chiến" ứng phó với biến đổi khí hậu.

8. Tác giả: Nguyễn Thị Thu Hoa (Lê Thị Toàn Vân) (Hội Nhà báo TP. Đà Nẵng) với tác phẩm: Cô Quảng và hành trình $6.144 \mathrm{~km}$.

9. Nhóm tác giả: Nguyễn Đình Hiếu (Hải Bình), Bùi Văn Động (Thái An) (LCH Ngân hàng) với loạt bài: Nông dân ngoại ô không được vay vốn tín chấp.

10. Nhóm tác giả: Nguyễn Tấn Phúc (Tấn Phúc), Nguyễn Hoài Thanh (Hoài Thanh) (HNB Hậu Giang) với loạt bài: Đồng bằng sông Cửu Long cơ hội "cất cánh".

11. Tác giả: Lê Hải (Hạ Long) (CH Tạp chí Cộng sản) với tác phẩm: Học bổng cho nông dân học nghề.

12. Tác giả: Nguyễn Thanh Tùng (Thanh Tùng) $(\mathrm{CH}$ Báo Đầu tư) với tác phẩm: Economy's Green 
Coloured Vision - Tầm nhìn xanh cho nền kinh tế.

13. Tác giả: Hồng Thanh (HNB Hải Phòng) với tác phẩm: Phát huy vai trò của tổ chức cơ sở Đảng trong doanh nghiệp.

14. Tác giả: Lưu Nhi Dũ (HNB TP. Hồ Chí Minh) với tác phẩm: Y đức và hoa hồng.

15. Nhóm tác giả: Đinh Ngọc Quảng (Trung Hiếu), Trần Thị Mỹ Duyên (Mỹ Thanh) (HNB TP. Hồ Chí Minh) với loạt bài: Cuộc chiến cam go với ma túy.

16. Tác giả: Nguyễn Duy Tuấn (LCH Bộ Thông tin và Truyền thông) với loạt bài: Innov Green đang làm gì trên biên giới Việt Nam?

17. Tác giả: Phạm Anh Minh (Anh Minh) ( $\mathrm{CH}$ Báo Đầu tư) với tác phẩm: Câu chuyện dài như con đường.

18. Nhóm tác giả: Lê Nguyễn Ái Chân (Ái Chân), Phạm Thị Loan (Đường Loan) (HNB TP. Hồ Chí Minh) với loạt bài: Bộ mặt thật về mục sư tự phong Nguyễn Hồng Quang.

19. Tác giả: Phạm Thanh Khương (Lù Pò Khương) (LCH Biên phòng) với tác phẩm: Hồi sinh tộc người Đan Lai.

20. Nhóm tác giả: Trần Thanh Tường, Nguyễn Ngọc Ước, Nguyễn Đại Hoàng, Vũ Đức Thuận (CH Báo Đại đoàn kết) với loạt bài: Xây dựng mô hình nông thôn mới còn nhiều bất cập.

21. Tác giả: Đức Tám (LCH Thông tấn xã Việt Nam) với tác phẩm ảnh: Thủ tướng Nguyễn Tấn Dũng chúc mừng Giáo sư Ngô Bảo Châu.

22. Tác giả: Nguyễn Hoài Linh (Hoài Linh) (Báo Tuổi trẻ TP Hồ Chí Minh) với tác phẩm ảnh: Những khoảnh khắc lịch sử của Giáo sư Ngô Bảo Châu.

23. Tác giả: Trần Vĩnh Nghĩa (CH Tạp chí Thủy sản) với tác phẩm ảnh: Kỳ vĩ mũi Kê Gà.

24. Nhóm tác giả: Mạc Văn Chung, Nguyễn Quý Mạnh Minh (LCH Bộ Văn hóa - Thể thao \& Du lịch) với tác phẩm: Lời ru thì buồn.

25. Tác giả: Cao Tuấn (HNB Phú Thọ) với tác phẩm: Chuyện nhỏ mà không nhỏ.

26. Nhóm tác giả: Đàm Trung, Đàm Trình (HNB Cao Bằng) với tác phẩm: Khi Cao Vít trở về.

27. Nhóm tác giả: Đinh Nhiên, Nguyễn Hưng (HNB Quảng Ninh) với tác phẩm: Chuyện nông dân nuôi bò sữa làm giàu.

28. Tác giả: Quốc Tuấn ( $\mathrm{LCH}$ Đài Truyền hình kỹ thuật số VTC) với tác phẩm: Cần quan tâm đầu tư nhiều hơn đến công tác tìm kiếm cứu nạn. 
29. Nhóm tác giả: Thành Công, Thu Thảo (HNB Hải Dương) với tác phẩm: Ông bố của những chú gà mái rô bốt.

30. Nhóm tác giả: Nguyễn Thu Hồng (Thu Hồng), Hoàng Tùng (HNB TP. Đà Nẵng) với tác phẩm: Cô Chính làm từ thiện.

31. Nhóm tác giả: Minh Triều, Bạch Hải (HNB Ninh Thuân) với tác phẩm: Nhà khoa học người Chăm.

32. Nhóm tác giả: Phạm Hùng, Hùng Trường, Ngọc Anh (HNB Hà Nam) với tác phẩm: Các loài thủy sản ở Hà Nam đang bị tiêu diệt.

33. Nhóm tác giả: Đoàn Xuân Thắng, Bùi Cường (HNB Quảng Bình) với tác phẩm: Đảng viên "4 cùng".

Hội đồng Giải báo chí quốc gia

Nguồn tin: Ban Nghiệp vụ 